\title{
Nível tecnológico e organizacional da cadeia produtiva da bubalinocultura de corte no estado do Maranhão
}

\author{
Technological and organizational level of the production chain of cutting in \\ buffaloes Maranhão state
}

\author{
Cleide Lis Ribeiro dos Santos' ${ }^{1}$, João Batista dos Santos Júnior ${ }^{1}$, Maylson Coutinho da Cunha', \\ Sérgio Roberto Ferreira Nunes ${ }^{1}$, Danilo Cutrim Bezerra², José Ribamar de Souza Torres Júnior², \\ Nancyleni Pinto Chaves ${ }^{1 *}$
}

\begin{abstract}
RESUMO: O objetivo deste trabalho foi traçar os níveis tecnológico e organizacional da cadeia produtiva da bubalinocultura de corte no estado do Maranhão, pesquisando os perfis dos produtores, industriais, distribuidores e consumidores, em relação aos aspectos de produção, tecnologia, gestão e aceitação da carne bubalina. Foram utilizados o método quantitativo para levantamento e análise de dados secundários, o método de natureza qualitativa e a aplicação de questionários. As análises realizadas com base nos dados coletados permitiram determinar algumas características desse segmento, tais como: quantitativo de búfalos para corte, nível de escolaridade dos produtores, tamanho da área de criação, divisão por categoria animal, tipo de exploração, atividades complementares de exploração, raças, identificação animal, sistema de criação, mercado da carne, organizaçáo dos custos de produção, usufrutos dos sindicatos e das cooperativas, principais problemas na criação, expansão do mercado, diferenças comparativas com os bovinos, consumo e aceitaçáo da carne para consumo. Conclui-se que a cadeia produtiva da bubalinocultura de corte no estado do Maranhão está em fase de organização, fato que pode ser reestruturado por meio da contribuiçáo e do comprometimento de todos os elos que a constituem.
\end{abstract}

PALAVRAS-CHAVE: búfalos; produção de carne; gestão; Maranhão.

\begin{abstract}
The objective of this study was to establish the technological and organizational level of the production chain of cutting buffaloes in the State of Maranhão, researching the backgrounds of the producers, manufacturers and distributors and consumers in relation to aspects of production, technology, management, and acceptance of the buffaloes meat. We used the quantitative method for collection and analysis of secondary data, the method of qualitative and survey questionnaires. Analyses conducted on the basis of collected data allowed to determine some characteristics of this segment, such as quantitative buffaloes to cut, education level of farmers, size of the breeding area, division by animal category, type of operation, complementary activities of exploration, races, animal identification, breeding system, meat market, organization of production costs, usufruct of unions and cooperatives, the major problems in the creation, market expansion, comparative differences with cattle, meat consumption, and acceptance of meat consumption. We conclude that the productive chain cutting buffaloes in the State of Maranhão is in flux, which can be restructured through the contribution and commitment of all the links that make it up.
\end{abstract}

KEYWORDS: buffaloes; meat production; management; Maranhão. 


\section{INTRODUÇÃO}

Os búfalos são animais de origem asiática, da família Bovidae, subfamília Bovinae, espécie Bubalus bubalis; são extremamente rústicos e apresentam alta capacidade de adaptação, podendo sobreviver em diversos ambientes, com grandes variaçôes de clima, relevo e vegetaçáo. São animais explorados para a produçáo de carne, a tração animal e as produçóes de esterco e de leite. Encontrados, praticamente, em todos os continentes, particularmente na Ásia (Índia, Paquistão, Tailândia, China e Vietnã), África (Egito), Europa (Itália) e América do Sul (Brasil, Argentina, Venezuela, Peru e Colômbia) (FAO, 2006; Lourenço Júnior; Garcia, 2008; Bernardes, 2011).

A bubalinocultura é uma atividade recente no Brasil, mas este já é o maior detentor do rebanho da América do Sul, seguido por Venezuela, Argentina e Colômbia (ANDrighetto et al., 2005). Os búfalos chegaram ao país no fim do século XIX, oriundos da Europa, do Caribe e da Ásia, e foram instalados inicialmente na região Norte, na Ilha de Marajó (estado do Pará); depois se expandiram por toda a regiáo e outras regióes do país. Inicialmente esses animais foram trazidos apenas por curiosidade, sem nenhum interesse econômico e comercial (BERNARDES, 1997; LOURENÇO JÚNIOR; Garcia, 2008).

O rebanho bubalino brasileiro concentra-se principalmente na região Norte do País (65\% do efetivo total), distribuído entre as raças Carabao, Murrah, Jafarabadi e Mediterrâneo (Marques; Cardoso, 1997; Lourenço Júnior; Garcia, 2008). O estado do Maranhão ocupa a segunda posição, com um efetivo bubalino de 86.648 cabeças (Maranhão, 2012).

Os produtores brasileiros notaram o potencial de mercado desses animais para a produção de carne e passaram a investir na bubalinocultura. De acordo com dados da Organização das Naçôes Unidas para Alimentação e Agricultura (FAO), de 1961 a 1980 o rebanho brasileiro evoluiu 686\% e de 1980 a 2005 o crescimento foi de $143 \%$; enquanto a evolução da produção de frangos nos mesmos períodos foi, respectivamente, de 234 e $149 \%$; a de bovinos, de 112 e $61 \%$; a de suínos, de 34 e -3\%; e a de ovinos, de 31 e -23\% (FAO, 2006).

A cadeia de carne bovídea apresenta posição de destaque na economia brasileira, ocupando vasta área do território nacional, e responde pela geração de emprego e renda de milhóes de brasileiros. O conjunto de agentes que a compóem apresenta grande heterogeneidade: de pecuaristas altamente capitalizados a pequenos produtores empobrecidos, de frigoríficos com alto padrão tecnológico, capazes de atender a uma exigente demanda externa, a abatedouros que dificilmente preenchem requisitos mínimos da legislação sanitária (Buainain; Batalha, 2007).

Para Zylbersztajn et al. (1993) e Jank et al. (1999), a cadeia produtiva é constituída por uma sequência de operaçóes interdependentes que têm por objetivo produzir, modificar e distribuir um produto. Tratando-se de cadeias produtivas agroindustriais, engloba as atividades de apoio à produção agropecuária (fornecimento de insumos, assistência técnica, pesquisa, etc.), a produção agropecuária dentro da fazenda, o seu armazenamento, o beneficiamento, a transformaçáo industrial e a distribuição (atacado e varejo) de um produto, in natura ou transformado, até o consumidor final. Os atores da cadeia produtiva são os produtores, industriais, distribuidores e consumidores, que são os tomadores de decisão e podem influenciar e interferir em sua coordenação.

A pecuária de corte participa significativamente na formação do produto interno bruto, sendo um dos setores mais importantes do agronegócio na economia brasileira. Porém, diversos setores da indústria e do comércio de carnes operam ainda por meio de sistemas desatualizados e com métodos arcaicos (JoRGe, 2005) e, para a bubalinocultura de corte, não é diferente.

Nesse contexto e em face à escassez de informaçóes disponíveis sobre a bubalinocultura de corte, realizou-se esta pesquisa com o objetivo de traçar os níveis tecnológico e organizacional da cadeia produtiva da bubalinocultura de corte no estado do Maranhão.

\section{MATERIAL E MÉTODOS}

\section{Tipologia e local de estudo}

O estudo possui um desenho exploratório com uma abordagem quantitativa e qualitativa. Foi realizado no estado do Maranhão, que apresenta uma área territorial de $331.983,293 \mathrm{~km}^{2}$, localizado a noroeste da regiāo Nordeste do Brasil. Limita-se ao Norte pelo Oceano Atlântico, ao Sul e ao Sudoeste pelo estado do Tocantins, ao Leste e ao Sudeste pelo estado do Piauí e a Oeste pelo estado do Pará e conta com 217 municípios, com uma população estimada em 6.103 .327 habitantes (IBGE, 2011).

\section{Levantamento de dados}

\section{Quantitativo}

A presente pesquisa abordou inicialmente o método quantitativo, por meio do levantamento de dados secundários em documentos, sites e materiais de institutos de pesquisa e de organizaçóes produtivas públicas e privadas para obter o quantitativo de bubalinos existentes no estado do Maranhão e a relação dos municípios que detêm essa criação.

Para o levantamento desses dados, foram utilizadas informaçóes do Instituto Brasileiro de Geografia e Estatística (IBGE), da Agência de Defesa Agropecuária do Maranhão (AGED - MA), do Instituto de Agronegócios do Maranhão (INAGRO), da Secretaria Municipal de Agricultura, Pesca e 
Abastecimento (SEMAPA), da Organização das Naçôes Unidas para Agricultara e Alimentação (FAO) e de associaçóes de produtores de carne bubalina do estado do Maranháo.

\section{Qualitativo}

Esta pesquisa também abordou o método qualitativo para firmar conceitos e objetivos a serem alcançados e dar sugestóes sobre variáveis a serem estudadas com maior profundidade. Os métodos qualitativos apresentam uma mistura de procedimentos de cunho racional e intuitivo, capazes de contribuir para melhor compreensão dos fenômenos (Giovinazzo, 2001).

\section{Pesquisa de campo}

Foram realizadas entrevistas com questionário semiestruturado com os produtores, industriais do setor frigorífico, distribuidores (marchantes) e consumidores de carne bubalina, mediante a assinatura do termo de consentimento livre e esclarecido, no período de março a julho de 2013. Nesse momento, foi procedida a observaçáo de fatos, para confirmar os dados coletados previamente e compreender aspectos produtivos, tecnológicos e de gestáo da atividade de produção de bubalinos de corte. Para as análises descritivas das informaçôes, o método qualitativo serviu de suporte.

\section{Coleta de Dados}

Para coletar dados com os produtores, industriais do setor frigorífico, distribuidores (marchantes) e consumidores de carne bubalina, a amostragem foi não probabilística, pois as unidades amostrais foram selecionadas de acordo com o acesso aos entrevistados e as restriçóes de tempo e orçamento, visando otimizar os resultados da pesquisa. Portanto, a amostra não foi sorteada, mas restrita aos elementos que estavam prontamente acessíveis.

\section{Georreferenciamento dos dados}

Para o georreferenciamento dos dados, utilizou-se aparelho de navegação GPS (Posicionamento Global por Satélite) da marca Garmin ${ }^{\circ}$, com acurácia de aproximadamente dois metros, para tomada de coordenadas geográficas dos municípios do estado do Maranháo com presença de bubalinos. Dessa forma, cada endereço foi localizado em um ponto no espaço. Para a confecção dos mapas temáticos, utilizou-se o software Terra View.

\section{Análise de dados}

As informaçôes dos questionários, assim como as coordenadas, foram armazenadas em um banco de dados utilizando o programa Microsoft Access ${ }^{\ominus}$. Utilizou-se a análise estatística descritiva por meio de distribuiçóes absoluta e relativa para expressar os dados obtidos nesta pesquisa.

\section{RESULTADOS E DISCUSSÃO}

O rebanho bubalino do estado do Maranhão é composto por 86.648 animais, distribuídos em 146 municípios dos 218 que compóem o Estado.

De acordo com a pesquisa realizada, o rebanho bubalino do Estado está em sua maioria concentrado na Baixada Maranhense $(\mathrm{n}=56.321 ; 65 \%$ do total $)$ (Fig. 1). Os 35\% restantes $(\mathrm{n}=30.327)$ estấo distribuídos de forma bastante pulverizada em pequenos criatórios localizados em 125 municípios maranhenses.

A Baixada Maranhense, formada por 21 municípios, detém uma área de 1.775.035,6 hectares e situa-se no Noroeste do Estado (1 ${ }^{\circ} 00^{\prime}-4^{\circ} 00^{\prime} \mathrm{S}$ e $\left.44^{\circ} 21^{\prime}-45^{\circ} 21^{\prime} \mathrm{W}\right)$. Corresponde a uma área de transição entre a Amazônia e o Nordeste e constitui um eco-complexo que inclui rios, lagos, estuários, agroecossistemas e áreas urbanas, além de campos naturais e um grande sistema de áreas inundáveis peculiares a essa regiáo, muito rico em fauna e flora. Seus ecossistemas mais representativos são: babaçual, campos inundáveis, manguezais, mata ciliar e floresta ombrófila (SANTOS, 2004; Bernardi, 2005).

A partir das décadas de 1950 a 1970, a Baixada Maranhense começou a apresentar expansáo na criação de búfalos, seja pela elevação no efetivo do rebanho bubalino, seja pelo aumento no número de propriedades envolvidas nessa atividade ou, ainda, pelo incentivo do governo ao programa de introduçáo de bubalinos no Estado, financiando criadores. Entretanto, isso ocorreu, com uma visão simplista na época, em função da experiência obtida com a criação de búfalos na Ilha de Marajó, cujas características acreditavam serem as mesmas da Baixada Maranhense (SANTOS, 2004).

Atualmente, o estado do Maranháo apresenta 1.551 produtores de bubalinos. Desse total, foram entrevistados 30 criadores, que se dispuseram a participar do estudo, todos da Baixada Maranhense, mais especificamente dos municípios de Viana (maior detentor de rebanho bubalino no estado) e Cajari. De acordo com as entrevistas realizadas, pôde-se constatar que a produção de búfalos para corte é realizada, na sua maioria $(\mathrm{n}=21 ; 70 \%)$, por unidades familiares, sendo a administração da propriedade rural realizada somente pelo proprietário ou pelo proprietário e membros da família. Observou-se também que o nível de escolaridade dos produtores oscila do ensino fundamental ao ensino superior, sendo o fundamental completo o predominante $(\mathrm{n}=18 ; 60 \%)$.

A concentração fundiária, na Baixada Maranhense, é elevada e representa padróes de uso da terra de baixo nível tecnológico, com baixa produtividade e gradativo processo de degradação dos recursos naturais. Estabelecimentos agropecuários maiores que 500 ha representam aproximadamente menos de $1 \%$ do total na maioria dos municípios dessa região, mas ocupam entre 30 e 70\% de suas áreas (BERNARDi, 2005).

Dos entrevistados, apenas 30\% são proprietários da área onde os búfalos são criados, e estas apresentam proporçóes bastante diferenciadas (variando de 10 a 49 ha na maioria dos casos para mais de 500 ha na minoria deles). A maioria ( $\mathrm{n}=21 ; 70 \%)$ 
náo apresenta propriedade rural, criando os animais totalmente soltos nos campos da Baixada Maranhense. Em 96,67\% ( $\mathrm{n}=29)$ dos casos, predomina a criação de baixo padrão tecnológico.

Os produtores foram divididos em 4 grupos quanto ao quantitativo de animais, ou seja, produtores com rebanhos de

1. até 18 animais, $(\mathrm{n}=15$ produtores);

2. 79 animais ( $\mathrm{n}=6$ produtores);

3. 261 animais ( $\mathrm{n}=7$ produtores); e

4. até 749 animais ( $\mathrm{n}=2$ produtores).

Os rebanhos apresentavam a seguinte categorização animal: fêmeas adultas $(50,30 \%)$, bezerras $(13,96 \%)$, novilhas $(13,55 \%)$, bezerros (11,68\%), novilhos (5,35\%) e machos adultos $(5,16 \%)$.

Foi relatado pelos produtores que o manejo dos animais é realizado pelo proprietário, com auxílio da família, e todos contam com funcionários (vaqueiros), variando em número de 1 a 4 . Além da produção de carne, existem outras atividades complementares que podem gerar renda, como a venda de bezerros $(100 \%)$ e a produção de leite $(60 \%)$. Foi possível observar a predominância de animais mestiços das raças Murrah, Jafarabadi e Mediterrâneo (89\%) e alguns animais puros, com destaque para a raça Murrah.
Por meio das entrevistas, observou-se que a reposição dos animais é realizada pelo próprio rebanho, no qual são retidas as fêmeas com melhores características genéticas; para a reprodução, são adquiridos touros mestiços (principalmente 5/16 da raça Murrah) ou de raças puras de origem, de produtores locais $(54,28 \%)$ e de criadores de municípios vizinhos (8,57\%).

Todos os produtores realizam a reprodução por meio de monta a campo, pois para a utilização da inseminação artificial ainda existem muitas barreiras, com destaque para a infraestrutura deficiente, a falta de mão de obra especializada, a dificuldade na aquisição do sêmen e também a falta de informaçóes por parte do produtor. Pequena parcela dos entrevistados ( $\mathrm{n}=1 ; 3,33 \%)$ realiza o registro genealógico dos animais. A maioria dos produtores $(\mathrm{n}=29 ; 96,67 \%)$ realiza a identificação dos animais por marcação a ferro candente e picotes/assinalamento na orelha.

A modalidade de criação de búfalos predominantemente é o sistema extensivo $(\mathrm{n}=26 ; 86,70 \%)$ em pastagens nativas e de baixa qualidade. Isso se deve em grande parte ao preconceito inicial de que a criação de búfalos somente seria viável em locais onde não se podem criar outros animais domésticos — tais como regióes pantanosas, sujeitas a enchentes,

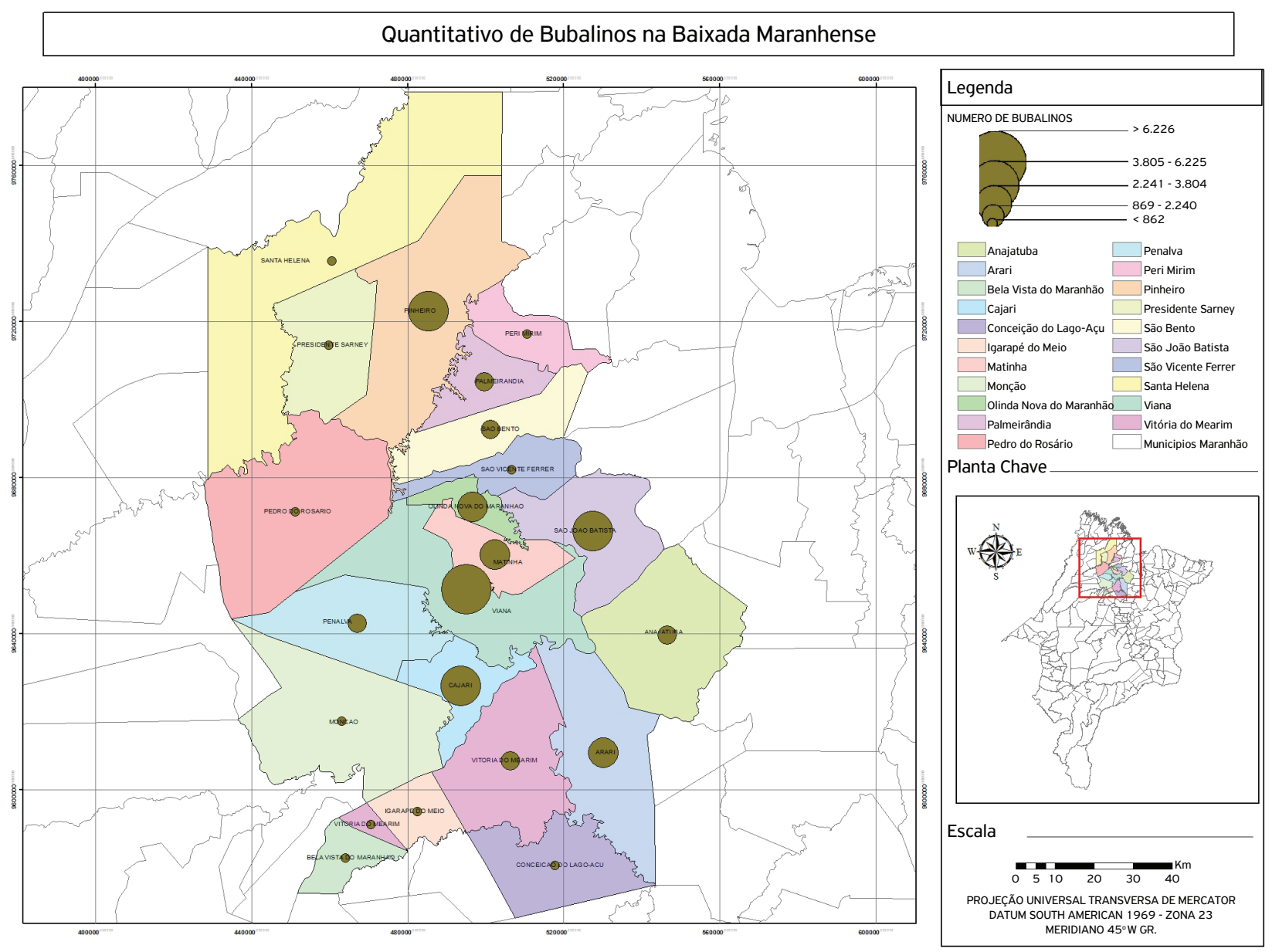

Figura 1. Quantitativo de bubalinos (Bubalus bubalis) para corte na Baixada Maranhense, 2013. 
de solos pobres - e terrenos montanhosos. Apesar disso, o búfalo é bastante resistente à seca, não tolerando muito bem áreas sem sombreamento, na ausência de água. Aos três anos, já pode ser abatido, e as fêmeas podem ser cruzadas entre 17 e 24 meses, segundo relato dos produtores.

De acordo com informaçóes obtidas com os produtores, há uma nítida superioridade produtiva dos bubalinos quando comparados aos bovinos, mesmo nas condiçôes de criação utilizadas. Na Tabela 1 são discriminados os índices zootécnicos dos bubalinos criados na Baixada Maranhense. Esses índices assemelham-se a alguns dados de desempenho encontrados por Kasprzyкоwski (1978) em pesquisa realizada no município de Pinheiro, pertencente à Baixada Maranhense.

Entretanto, a baixa rentabilidade da bubalinocultura nos sistemas tradicionais de criação, como o praticado com expressividade na Baixada Maranhense, tornou essa atividade pouco atrativa economicamente. Esse fato tem induzido alguns pecuaristas a transferirem parte dos búfalos para áreas já formadas com pastagens cultivadas em terra firme e a realizar investimentos na recuperaçáo de áreas alteradas como forma de elevar a produtividade e tornar a criaçáo mais competitiva. Essa mudança foi relatada por 3,33\% $(\mathrm{n}=1)$ dos entrevistados.

Durante muito tempo, a bubalinocultura realizada no estado do Maranhão concentrou-se na produçâo de carne. Mas, ultimamente, a exploraçáo leiteira começa a ocupar espaços. Os produtores acreditam que, em futuro muito próximo, a produção intensiva de carne e leite de búfalos em sistemas agrossilvipastoris, em pastejo rotacionado intensivo em terra firme, torne-se plenamente sustentável dos pontos de vista biológico, econômico, ambiental e social, com produtividade três a cinco vezes superior à dos sistemas de criação tradicionais. A adoção de tecnologia permitirá a recuperação de áreas degradadas, diminuindo a pressão pelo desmatamento de novas áreas de floresta. A sociedade será beneficiada na medida em

Tabela 1. Índices zootécnicos dos bubalinos criados na Baixada maranhense, 2013

\begin{tabular}{lc} 
Índices zootécnicos & Espécie bubalina \\
\hline Índice de natalidade & 20 a $58 \%$ \\
\hline Vida útil do reprodutor & 12 a 14 anos \\
\hline Número de crias por matriz & 8 a 10 \\
\hline Idade do primeiro parto & 3 anos \\
\hline Período de gestação & 10 meses \\
\hline Intervalo entre partos & 18 meses \\
\hline Período de lactação & 8 a 10 meses \\
\hline Produção de leite/dia & 3 a 3,5 litros \\
\hline Peso ao nascer & $28 \mathrm{~kg}$ \\
\hline Idade da desmama & 8 a 10 meses \\
\hline Peso vivo adulto & $600 \mathrm{~kg}$ \\
\hline Idade de abate & 3 a 4 anos \\
\hline Peso vivo á idade de abate & 430 a $600 \mathrm{~kg}$ \\
\hline Mortalidade de bezerros & 4 a $10 \%$ \\
\hline
\end{tabular}

que a pecuária bubalina contribui efetivamente para manter o homem no campo, evitando o êxodo rural - gera empregos no beneficiamento, no transporte, na distribuição e na comercialização dos produtos e subprodutos do búfalo em toda a cadeia produtiva.

Para a Concremat Engenharia (2002), o búfalo criado em áreas sem nenhum sistema de manejo produtivo implementado provoca um violento impacto ambiental na regiáo por danificar a vegetação quando comparado ao bovino; compactar os solos; comprometer a qualidade das águas; além de comer plantas terrestres e aquáticas reguladoras de ecossistemas e destruir ninhos de espécies da fauna local, comprometendo a biodiversidade.

Apesar da criação de búfalos ser majoritariamente realizada sem nenhum sistema de manejo produtivo implementado, sem preocupação com o comprometimento da fauna, da flora, da água e do solo de um território, há várias experiências exitosas de criação de búfalos com a finalidade de produzir carne ou leite que realizam um manejo adequado e têm resultado em benefícios para o ambiente, o criador e outros atores sociais de uma determinada regiáo (BERNARDI, 2005).

De acordo com Nantes; SCARPelli (2008), em decorrência da globalização, no mercado de alimento, as margens de lucros estáo cada vez menores, levando as propriedades rurais a desenvolver um novo posicionamento, praticando uma agropecuária moderna e ligada às agroindústrias ou aos canais de distribuição para que possam ser competitivas. Para ser competitiva, é preciso que as unidades produtivas busquem novos modelos de gestáo e operação, visando ter um produto com os padrôes de qualidade definidos pelo consumidor final.

$\mathrm{Na}$ pesquisa em questão, observou-se que em $100 \%$ $(\mathrm{n}=30)$ das propriedades a produção de búfalo para abate é o principal fator para geração de receita, ficando a comercializaçáo de leite e bezerros em segundo plano. Entretanto, nenhum dos entrevistados comercializa os búfalos diretamente para as indústrias frigoríficas, realizando o comércio de animais com marchantes da Baixada Maranhense e de outros municípios, inclusive da região metropolitana do estado. Estes, com os entrepostos de carne (lojas varejistas) e, finalmente, para o consumidor final. Portanto, fica claro que o mercado para a venda de búfalo na Baixada Maranhense é bastante limitado pela inexistência de frigoríficos e pelo reduzido número de compradores próximos, ficando os produtores dependentes de compradores de outras regióes do estado.

Dessa forma, o produtor náo escolhe a empresa com a qual irá comercializar seu produto. Mas o critério mais mencionado de comercialização foi o preço, em seguida vem a seriedade na negociação, a fidelização do cliente, a proximidade e a facilidade de entrega. Apesar de ser a variável mais mencionada (preço), 100\% ( $\mathrm{n}=30)$ dos entrevistados não estấo satisfeitos com o preço pago, variando entre $\mathrm{R} \$ 5,00$ e $\mathrm{R} \$ 6,00 / \mathrm{kg}$ de carne. $\mathrm{O}$ argumento para a não satisfação é que, por esse preço e pela média produzida por búfalo, apenas é possível 
cobrir os custos de produção, não há renda suficiente para a manutenção da família. Essa renda é complementada com a comercialização de leite e bezerros. Porém, apenas 3,33\% ( $\mathrm{n}=1$ ) dos entrevistados realizam o controle de custos da produção.

Apesar de serem poucas as organizaçóes sindicais do setor, foi possível observar que $10 \%(n=3)$ dos entrevistados pertencem a alguma associação sindical, mesmo que seja de outro setor, e também alguns são sócios de cooperativas. Para eles, o sindicato oferece algumas vantagens, como assistências jurídica, contábil e trabalhista, troca de informaçóes e palestras, e as cooperativas disponibilizam informaçôes sobre o mercado. Para o suporte financeiro na produção, apenas 46,67\% ( $\mathrm{n}=14$ ) dos proprietários utilizam financiamentos bancários, os demais trabalham com ativos próprios para implementação e desenvolvimento das atividades.

Os principais problemas enfrentados para a criação de bubalinos, segundo os entrevistados, são: $1^{\circ}$ infraestrutura ( $\mathrm{n}=30 ; 100 \%) ; 2^{\circ}$ mão de obra $(\mathrm{n}=25 ; 83,34 \%)$; $3^{\circ}$ mercado restrito ( $\mathrm{n}=12 ; 40 \%) ; 4^{\circ}$ preconceito com a criação $(\mathrm{n}=11 ; 36,67 \%) ; 5^{\circ}$ custo de produção ( $\left.\mathrm{n}=11 ; 36,67 \%\right)$.

Em relaçáo à infraestrutura, o fato de a maioria dos produtores não terem áreas para a criação de bubalinos corresponde a um dos maiores entraves na criação desses animais. Segundo os entrevistados, a bubalinocultura também exige grandes áreas para acomodação de machos na pastagem, uma vez que há disputa dessa categoria em uma mesma área, o que demanda maiores áreas e seu conseguinte cercamento. Como é um animal mais pesado, é preciso haver um processo de rotação nas pastagens, para que estas se recuperem do pisoteio.

$\mathrm{Na}$ questão da mão de obra, o problema refere-se principalmente à falta de especialização para a atividade. Em relação aos gastos na atividade, segundo os produtores entrevistados, o custo de produção torna-se muito alto se acrescentado à alimentação dos animais produtos concentrados e energéticos (suplementação para aumentar produção), pois, mesmo com o aumento da produtividade, financeiramente não é vantajoso (na relação custo-benefício).

O mercado restrito para a carne bubalina também foi relatado pelos industriais do setor frigorífico e distribuidores (marchantes) entrevistados (no total, foram entrevistadas 30 pessoas desse setor da cadeia produtiva da carne bubalina). Muitos encontram dificuldades $(n=12 ; 40 \%)$ para comercializar esses animais. Associado a isso, o preço pago por quilo dessa carne poderia ser mais atrativo, dado o diferencial que o produto oferece comparativamente à carne bovina, para que o produtor pudesse ter uma rentabilidade maior.

Quanto ao mercado restrito, como mencionado anteriormente, esses animais comercializados com marchantes da Baixada Maranhense e de outros municípios são abatidos em sua grande maioria em abatedouros municipais, que não preenchem requisitos mínimos da legislação sanitária.

Outro ponto destacado por produtores, industriais e distribuidores é o preconceito com os búfalos e seus subprodutos.
Para os entrevistados, essa fonte proteica é pouco difundida e permeada de tabus quanto às características do animal, como sistema de criação, degradação ambiental, cor da pelagem, cor da carne e mitos sobre a transmissão de doenças. Dessa forma, 93,33\% ( $\mathrm{n}=28)$ dos industriais e dos distribuidores utilizam artifícios para mascarar esse produto e vendê-lo como carne bovina - os mais citados foram: pendurar a orelha e a ponta da cauda de bovinos na carcaça bubalina, utilizar a carne de sangria de bovinos para passar em toda a extensão da carcaça bubalina e transformar cortes cárneos em carne moída.

Segundo a SEMAPA (2012) e três proprietários de frigoríficos da Região Metropolitana do estado do MA, nos anos de 2010 a 2011, foram abatidos 7.531 bubalinos, sendo 5.156 machos $(68,5 \%)$ e 2.375 (31,5\%) fêmeas, com idades entre 24 e 48 meses. Mas, em função do preconceito, esses animais foram comercializados como bovinos, pois, em entrevista com os proprietários de entrepostos de carne, nesse mesmo período, não foram adquiridas carcaças de bubalinos para comercialização. Outro ponto importante é que, na comprovação sanitária emitida pelo Serviço de Inspeção, não existe nenhum item que comprove a espécie correspondente ao animal abatido nos frigoríficos.

É unanimidade entre esses elos da cadeia pecuária bubalina a necessidade premente de políticas de incentivo, a divulgação das vantagens produtivas, de manejo e rusticidade e de qualidade da carne bubalina. Para eles, esse produto deveria estar no mesmo patamar da carne bovina e, em um futuro próximo, associado logicamente aos investimentos, os búfalos responderão por $50 \%$ do fornecimento de proteína de alto valor biológico no estado do Maranhão.

Segundo a Embrapa Amazônia Oriental (2001), resultados de pesquisas comparando a carne do búfalo com a bovina revelam que a primeira apresenta $40 \%$ menos colesterol, 12 vezes menos gordura, 55\% menos calorias, $11 \%$ mais proteína e $10 \%$ mais minerais, sendo, portanto, mais indicada para a saúde humana.

Mas a carne bubalina é tratada e comercializada, em boa parte do país, sem uma forma definida de identificação das suas características, principalmente de qualidade ou do valor justo. Como a carne bovina, ela, também, é uma commodity, ou seja, vale quanto pesa. Sem uma diferenciação baseada na identificação da carne, do rendimento e na qualidade, deixa de existir o estímulo para que o setor produtivo se modernize e invista na obtençáo de um produto mais adequado, orientado para o atendimento dos desejos e anseios do consumidor (Jorge; Andrighetto, 2005; Bernardes, 2011).

A mudança de orientação do sistema produtivo da carne bubalina necessita urgentemente começar a se voltar para o consumidor. É o consumidor que diz o que quer comprar, quando, como e, mais importante ainda, quanto pode pagar pelo produto. Nesse sentido, é importante conhecer o valor relativo da carne bubalina quanto aos outros produtos 
similares, lembrando que o consumidor náo paga pelo aspecto nutricional, pela segurança ou pela qualidade, pois estes estão embutidos no preço (Jorge; ANdrighetTo, 2005).

De modo errôneo, a carne bubalina tem estado presente nas mesas dos consumidores maranhenses por conta dos estabelecimentos que empreendem a comercialização desta como carne bovina. Em confirmação, TonHaTi (2001) estimou que, na década de 1980, aproximadamente 30 mil toneladas de carne bubalina foram comercializadas no mercado brasileiro sendo consumidos como carne bovina. $\mathrm{Na}$ atualidade, pode ser que esse percentual tenha se elevado em vista ao aumento no rebanho bubalino (BerNardes, 2007). Entretanto, em meio a tantos adjetivos organolépticos e nutricionais (GIORDANO et al., 2010), a ausência de organização da cadeia produtiva e de iniciativa para o fortalecimento tem impossibilitado que tais atributos se revertam em aumento da lucratividade para a cadeia da carne bubalina, influindo negativamente para a estagnação da atividade.

Foram entrevistados 200 consumidores de diferentes bairros da capital do estado do Maranháo, por ser o local com maior volume de abate dessa espécie portando a maior comercializaçáo deste produto.

Os consumidores, em linhas gerais, mostraram-se pouco receptivos ao consumo da carne bubalina. Dos entrevistados, $89 \%(\mathrm{n}=178)$ nunca consumiram carne bubalina e $11 \%(\mathrm{n}=22)$ afirmaram já ter consumido ao menos uma vez. Esse fato deve-se principalmente à indisponibilidade do produto no mercado. As características e vantagens da carne bubalina sobre a bovina eram desconhecidas por $93 \%(\mathrm{n}=186)$ das pessoas entrevistadas. Mas $82 \%(n=164)$ destes afirmaram não substituir a carne bovina pela bubalina. Entre os motivos enumerados estáo: o desconhecimento (72,56\%), o hábito $(17,68 \%)$ e o preconceito com o animal (10\%), razóes que podem ser revertidas por meio do acesso à informação e à divulgação das características e das vantagens desse produto. Já os $18 \%(\mathrm{n}=36)$ que substituiriam o consumo pela carne bubalina motivam-se por ser saudável $(8,33 \%)$, magra $(19,44 \%)$, atrativa $(30,56 \%)$ e exótica $(41,67 \%)$.

Após esclarecimento de que a carne de búfalo preenche as exigências do mercado consumidor atual, que procura uma alimentação saudável mais indicada para a saúde humana e ao mesmo tempo saborosa, de boa aparência e muito suculenta, $85 \%(\mathrm{n}=170)$ dos entrevistados substituiriam a carne bovina com essa informação e somente $15 \%(n=30)$ não o fariam.

Informando que carne bubalina é mais magra, com menos colesterol e calorias e mais proteínas em relação à carne bovina, 98\% ( $\mathrm{n}=196)$ dos entrevistados afirmaram que passariam a consumir a carne bubalina, contudo, ainda $2 \%(\mathrm{n}=4)$ permaneceriam fidelizados à carne bovina.

Por fim, 43\% ( $\mathrm{n}=86)$ dos entrevistados não consideram justo agregar um valor superior à carne de búfalo em relação à bovina. Porém, $57 \%(\mathrm{n}=114)$ afirmaram aceitável a agregação de valor. Portanto, o consumidor se disponibiliza a pagar mais pelo produto que the confira vantagens nutricionais adicionais.

\section{CONCLUSÕES}

Com base nos resultados desta pesquisa, pode-se concluir que:

- A cadeia produtiva da bubalinocultura de corte no estado do Maranhão ainda está em baixo nível tecnológico e em fase de organização, necessitando também de grande investimento em marketing para esclarecimento e divulgação do produto.

- Existem diversos desafios a serem superados por esse setor, entre eles, competir com outras fontes de proteína, especialmente bovinos.

- Para competir nesse mercado, a pecuária bubalina terá que melhorar ainda mais seus índices de produtividade, criando identidade aos seus produtos, e atender às exigências dos consumidores em relação à segurança alimentar, à qualidade do produto e ao respeito ao meio ambiente.

\section{AGRADECIMENTOS}

À Fundação de Amparo à Pesquisa e ao Desenvolvimento Científico do Maranhão (FAPEMA) pelo suporte para a realização deste trabalho.
ANDRIGHETTO, C.; JORGE, A.M.; PICCININ, A. Efeitos da monensina sódica sobre a produção e composição do leite, a produção de mozzarela e o escore de condição corporal de búfalas murrah. Revista Brasileira de Zootecnia, Viçosa, v.34, n.2, p.641-649, 2005.

BERNARDES, W. Bubalinocultura leiteira no Brasil: tendências, parcerias e fomento. 1997. Palestra no evento sobre as perspectivas da bubalinocultura leiteira no país e sobre o programa de "fomento" desenvolvido pela Fazenda Paineiras da Ingaí. Disponível em: <http://www.ingai.agr.br/x/parceria.htm>. Acesso em: 13 set. 2013.

BERNARDES, O. Bubalinocultura no Brasil: situação e importância econômica. Revista Brasileira de Reprodução Animal. Belo Horizonte, v.31, n.3, p.293-298, jul./set, 2007. Disponível em: <www.cbra. org.br>. Acesso em: 9 set. 2013. 
BERNARDES, O. Integração, associativismo e arranjos na cadeia produtiva da bubalinocultura: situação atual e perspectivas. In: SIMPÓSIO DA CADEIA PRODUTIVA DA BUBALINOCULTURA, 2, 2011. Botucatu. Resumos. p.1-13.

BERNARDI, C.C. Conflitos sócio-ambientais decorrentes da bubalinocultura em territórios pesqueiros artesanais: o caso Olinda Nova do Maranhão. 2005. 216p. Dissertação (Mestrado - Planejamento e Gestão Ambiental) - Universidade Católica de Brasília, Brasília, 2005.

BUAINAIN, A.M.; BATALHA, M.O. Cadeia produtiva de carne bovina. Brasília: Ministério da Agricultura, Pecuária e Abastecimento, 2007. 85p. (Documento Técnico 001). Disponível em: <http: //www.iica.org.br/>. Acesso em: 13 set. 2013.

CONCREMAT ENGENHARIA. Execução do plano de gerenciamento participativo dos recursos hídricos da APA da Baixada Maranhense. São Luís: SEMA/IICA, 2002. 160p.

EMBRAPA AMAZÔNIA ORIENTAL. Linguiça defumada com corte secundário de baby búfalo. Belém: Ministério da Agricultura, Pecuária e Abastecimento, 2001. (Documento Técnico). Disponível em: <http:// www.infoteca.cnptia.embrapa.br/bitstream/doc/607613/1/ LinguicaDefumadaCPATU.pdf>. Acesso em: 13 set. 2013.

FAO. Organização das Nações Unidas para Agricultura e Alimentação. Dados da evolução do rebanho brasileiro, 2006. Disponível em: <http://www.faostat.org>. Acesso em: 13 set. 2013.

GIORDANO, G.; GUARINI, P.; FERRARI, P.; BIONDI-ZOCCAI, G.; SCHIAVONE, B.; GIORDANO, A. Beneficial impact on cardiovascular risk profile of water buffalo meat consumption. European Journal of Clinical Nutrition, v.64, n.9, p.1000-1006, 2010. Disponível em: <http://www.nature.com/ejcn/journal/v64/n9/full/ ejcn2010108a.html>. Acesso em: 28 out. 2015.

GIOVINAZZO, R.A. Focus Group em pesquisa qualitativa: fundamentos e reflexão. Administração On Line, São Paulo: FEA USP, v.2, n.4, 2001. Disponível em: < http://www.fecap.br/ adm_online/art24/renata2.htm>. Acesso em: 13 set. 2013.

IBGE. Instituto Brasileiro de Geografia e Estatística, 2011. Estados. Disponível em: <http://www. ibge.gov.com.br>. Acesso em: 13 set. 2013.

JANK, M.S.; FARINA, E.M.Q.; GALAN, V.B. O agribusiness do leite. São Paulo, Milkbizz, 108p, 1999. Disponível em: < http://www. sober.org.br/palestra >. Acesso em 10 set. 2013.
JORGE, A.M.; Produção de carne bubalina. Revista Brasileira de Reprodução Animal, Belo Horizonte, v.29, n.2, p.84-95, abril/ jun. 2005.

JORGE, A.M.; ANDRIGHETTO, C. Características de Carcaça de Bubalinos. In: CONGRESSO BRASILEIRO DE ZOOTECNIA DA ABCZ, 2005. Campo Grande. Resumos. p. 1-29.

KASPRZYKOWSKI, J.W.A. A criação de búfalos no Nordeste. Fortaleza: Etene, 1978. 48p.

LOURENÇO JÚNIOR, J. de B.; GARCIA, A.R. Panorama da bubalinocultura na Amazônia. 2008. Disponível em: <http:// www.alice.cnptia.embrapa.br/alice/bitstream/doc/409969/1/ LOURENCO2008AmazonpecPanorama.pdf >. Acesso em: 28 out. 2015.

MARANHÃO. Setor de Epidemiologia e Estatística, Coordenadoria de Defesa Animal, Agência Estadual de Defesa Agropecuária do Estado do Maranhão. Efetivo Bubalino. São Luís. 2012.

MARQUES, J.R.F.; CARDOSO, L.S. A bubalinocultura no Brasil e no Mundo. In: SIMPÓSIO BRASILEIRO DE BUBALININOCULTURA, 1., 1997, Cruz das Almas. Anais. p. 10-221.

NANTES, J.F.D.; SCARPELLI, M. Gestão da Produção Rural no Agronegócio. In: BATALHA, Mário O. Gestão Agroindustrial. $3^{a}$ ed. São Paulo: Atlas, 2008. p.556-583.

SANTOS, O.M. Avaliação dos usos e ocupação das terras da Bacia Hidrográfica do Rio Pericumã - MA, utilizando como parâmetros os padrões recomendáveis para uma área de proteção ambiental. 2004. 96 p. Dissertação (Mestrado - Sustentabilidade de Ecossistemas) Universidade Federal do Maranhão, São Luís, 2004.

SEMAPA. Secretaria Municipal de Agricultura, Pesca e Abastecimento. Volume de abate de bubalinos na Cidade de São Luís - MA. 2012.

TONHATI, H. Sistemas de produção de carne bubalina no Brasil: tecnologias e informações para o desenvolvimento sustentável. In: CONGRESSO NAZIONALE SULL'ALLEVAMENTO DEL BUFALO, 2001, Itália. Resumos. p. 269-272.

ZYLBERSZTAJN, D.; FARINA, E.M.M.Q.; SANTOS, R.C.O. O sistema agroindustrial do café: um estudo da organização e do agrobusiness do café visto como a chave da competitividade. Embrapa Meio Ambiente (CNPMA), Porto Alegre: Ortiz, 277p, 1993. 